\title{
Development of portable user-interactive holographic information collector for agricultural product markets
}

\author{
Shiwei $\mathrm{Xu}^{1,2,3^{*}}$, Denghua $\mathrm{Li}^{1,2,3}$, Yongen Zhang ${ }^{1,2,3}$, Wei Chen ${ }^{1,2,3}$, Jiayu Zhuang ${ }^{1,2,3}$, \\ Jiajia Liu ${ }^{1,2,3}$, Shengwei Wang ${ }^{1,2,3}$ \\ (1. Agricultural Information Institute of Chinese Academy of Agricultural Sciences, Beijing 100081, China; \\ 2. Key Laboratory of Agricultural Information Service Technology, Ministry of Agriculture and Rural Affairs, Beijing 100081, China; \\ 3. Research Center of Agricultural Monitoring and Early Warning Engineering Technology, Beijing 100081, China)
}

\begin{abstract}
The efficient and accurate collection of agricultural product market information serves as the basis for the effective regulation of agricultural product markets. To achieve a comprehensive, accurate, and timely collection of agricultural product market information, this study puts forth a technique for collecting holographic information of agricultural product markets. A portable human-machine interaction device with an Advanced RISC (reduced instruction set computer) Machines (ARM)-based processor as the core is developed. Holographic information such as agricultural product market trading time, trading place, product name, price, and trading volume can be collected. Via embedded technology and component technology, innovative agricultural product market positioning, and matching, standardized collection, and data processing, and in combination with intelligent algorithms for analysis and early warning, a mobile application terminal for information collection is developed, namely, a holographic information collector for agricultural product markets (named Nongxincai). By using a layered structure, the hardware integrates microprocessor, storage, power, application and communication interface, and human-machine interaction modules. The device has the advantages of miniaturization, the whole-machine power consumption of less than $0.5 \mathrm{~W}$, and continuous operating time of at least $10 \mathrm{~h}$. A supporting software system for Nongxincai has also been developed, in which Microsoft Windows Mobile 6.5 is employed as the operating system, and the CPU frequency is up to $600 \mathrm{MHz}$. This configuration fully meets the computing requirements of map processing and large-volume data processing and has high compatibility. Nongxincai has been popularized and applied in 12 provinces/municipalities in China. It has played an important role in the monitoring and early warning of different varieties of agricultural products and target prices of soybean and cotton.
\end{abstract}

Keywords: agricultural product market, holographic information, portable, user-interactive, information collector, monitoring and early warning

DOI: $10.25165 /$ j.ijabe. 20201303.5845

Citation: Xu S W, Li D H, Zhang Y E, Chen W, Zhuang J Y, Liu J J, et al. Development of portable user-interactive holographic information collector for agricultural product markets. Int J Agric \& Biol Eng, 2020; 13(3): 143-153.

\section{Introduction}

In recent years, as the price volatility of agricultural products, especially fresh agricultural products, has been aggravated, sudden and sharp rises and falls have occurred from time to time, and the pressure to maintain an effective supply of agricultural products and market stability has continued to increase ${ }^{[1]}$. Timely, comprehensive, and effective identification, tracking, monitoring, and grasping of abnormal market information is urgently needed to stabilize the agricultural product market. However, for a long

\section{Received date: 2020-04-10 Accepted date: 2020-05-03}

Biographies: Denghua Li, PhD, Associate Researcher, research interest: agricultural information monitoring, Email: lidenghua@caas.cn; Yongen Zhang, $\mathrm{PhD}$, Associate Researcher, research interest: agricultural information monitoring and early warning, Email: zhangyongen@caas.cn; Wei Chen, PhD, Associate researcher, research interest: agricultural information technology, Email: chenwei@caas.cn; Jiayu Zhuang, MS, Associate Researcher, research interest: agricultural information analysis, Email: zhuangjiayu@caas.cn; Jiajia Liu, MS, Assistant Researcher, research interest: agricultural information analysis, Email: liujiajia@caas.cn; Shengwei Wang, PhD, Assistant Researcher, research interest: agricultural information analysis, Email: wangshengwei@caas.cn.

*Corresponding author: Shiwei $\mathbf{X u}, \mathrm{PhD}$, Researcher, research interest: agricultural information monitoring and early warning. Mailing address: No.12 Zhongguancun South St., Haidian District, Beijing 100081, China. Tel: +86-10-82109902, Email: xushiwei@caas.cn. time, the collection of agricultural product market information has had serious issues. For instance, data collection is not timely, the content collected is not thorough, collection methods are not standardized, and collection efficiency is relatively low. Other problems include insufficient technical means for agricultural information acquisition and lack of high-performance, low-cost equipment for information collection. These problems make it difficult to meet the technical requirements of real-time and accurate product monitoring and early warning, which has become a bottleneck that restricts the stable development of modern agriculture $^{[2]}$.

With the explosion of mass information, agriculture has entered the era of big data, and intelligent, high-throughput, and instantaneous data acquisition and analysis technologies for agricultural information continue to make breakthroughs and find new applications ${ }^{[3-6]}$. In recent years, the Internet of thing ${ }^{[7,8]}$, wireless sensors ${ }^{[9,10]}$, agricultural remote sensing ${ }^{[11]}$, multichannel acquisition devices ${ }^{[12,13]}$, radio frequency identification (RFID) collectors $^{[14,15]}$, smart mobile terminals ${ }^{[16-18]}$, and other technologies and equipment have greatly improved the efficiency of agricultural information collection. The current research and related applications are mainly focused on collecting information on production processes in the agricultural industry chain, such as constructing software and hardware systems to collect soil 
temperature and moisture, meteorology, and crop vitality information during crop growth. There are few reports on the development of information collection technologies and equipment to analyze the agricultural product market. During the process of agricultural product market information collection, oral notes, filling out forms manually, reporting via the Internet or telephone, and other outdated information collection methods are generally used, which restrict the timeliness and accuracy of information acquisition. As a result, the contents of information collected are neither comprehensive nor clear, the standards are not uniform, and the information assessment of agricultural product markets has low comparability between regions ${ }^{[19]}$.

Internationally, to accurately obtain information on agricultural product markets and gather big data on agricultural products, the Agricultural Marketing Service of the United States Department of Agriculture has established an information collection team to collect information through questionnaires and other methods for establishing a robust resource of basic data, which is released monthly in the World Agricultural Supply and Demand Estimates $^{[20]}$. Australia has established a complete set of working mechanisms for information collection, analysis, and release. The Agricultural and Resource Economics and Sciences of Australia is mainly responsible for the collection of agricultural product data, including general agricultural statistics, livestock and livestock product information, crop and pasture information, agricultural land information, agricultural financial statistics, and product value information; the collection methods are mainly annual farm surveys, including detailed financial affairs, agricultural resources, and socioeconomic information $^{[21-23]}$. In Japan, the statistical centers of local agricultural administration bureaus collect market information for the monitored objects and report it to the Agricultural Statistics Division of the Ministry of Agriculture, Forestry and Fisheries of Japan. The Ministry of Agriculture, Forestry and Fisheries also generally mails survey questionnaires or sends emails to conduct agricultural statistical surveys, and agricultural producers, enterprises, and food industry chain-related personnel can report information by answering electronic surveys online $^{[24,25]}$. Internationally, traditional statistical surveys, for instance, followed by gradual reporting from a bottom level to an upper level, have been widely employed to collect agricultural product market information. Some individual regions and organizations have also actively used information technology to carry out mobile collection experiments for market information collection. For instance, Singh et al. ${ }^{[26,27]}$ utilized speech recognition systems and applied them to collect data in precision agriculture, and they designed and developed agricultural vehicles that were voice-controlled by multipurpose electronic control boxes. Daniel et al. ${ }^{[28]}$ developed an information acquisition system based on mobile platforms. However, such devices often have some shortcomings. For instance, the collected data is generally one-dimensional, the data accuracy is low, and the falsely collected data are hard to identify and remove efficiently. Additionally, the acquisition equipment is susceptible to the operating environment, such as rain, fog, snow, and light. More importantly, the equipment does not have the function of analysis and forecasting, leading to an inability to make predictions and early warnings. Furthermore, due to the differences in the agricultural product markets and management systems between China and other countries, the applicability of such related equipment in China is poor. The standardized, real-time data collection, low-power transmission, online processing of massive data, and other related technologies are not only challenging problems to be overcome by international peers but also key points to be addressed in China, promoting the research and development of technologies and equipment for agricultural product market information collection ${ }^{[29-31]}$.

The main reason for the poor performance of agricultural product market information collection lies in the fall-behind data collection methods and the lack of special equipment, monitoring, and analysis as well as an early warning system that could support data collection. Therefore, there is an urgent need to develop an information collector that is embedded, mobile, and intelligent. The main purpose of this study was to develop a user-interactive collector of holographic information on agricultural product markets. By employing embedded technology and component technology and by adopting a new design concept to optimize the hardware and software structure, the Nongxincai equipment and supporting systems were developed. Through the innovation of agricultural product market positioning and matching, standardized collection, data processing and analysis, and early warning technologies, a holographic information collection method for agricultural product markets was established. It provides an effective means for the collection, analysis, and early warning of agricultural product market information. Nongxincai has been popularized and applied in 12 provinces/municipalities in China and has played an important role in the national monitoring of and early warning about agricultural products and target prices of soybean and cotton.

\section{Design of information collection system framework}

\subsection{Design background and general idea}

The timely, accurate, and efficient collection of agricultural product market information serves as the basis for market regulation and market risk avoidance. The research and development of holographic information collection technology and equipment for agricultural product market have focused on a complete technical system, in which standardized information collection is the guideline, real-time positioning and matching are the basis, the design of a highly adaptable market information collector is the core, and systematic market information processing, analysis, and early warning are the key. Nongxincai is the basic device for monitoring and early warning about the agricultural product market. It integrates a mobile terminal, database server, and system platform in a "three-in-one" manner (Figure 1). By integrating global positioning system (GPS), geographic information system (GIS), and general packet radio service (GPRS) as well as $3 \mathrm{G} / 4 \mathrm{G}$ mobile communication technology, and adopting component technology, embedded technology, and other related technologies, it has provided data upload and the release of collection commands for agricultural product market information. On the one hand, the mobile collection terminal allows the real-time standardized and dynamic collection of market information. On the other hand, when the market changes abnormally, the central terminal of the system can issue collection instructions to obtain real-time market information in a targeted manner and start an emergency collection program.

The server hardware of the data processing and application system in Nongxincai includes an integrated application server, database server, GIS server, network switch, load-balancing equipment, firewall, intrusion prevention equipment, web application firewall, and other equipment. Specifically, Windows server 2008 64-bit (Standard edition) is used as the database server operating system (OS). Microsoft Structured Query Language 
(SQL) Server 2008 (Enterprise edition) is used as the database, which is responsible for receiving market data (such as agricultural product prices) as well as the analysis and processing of reported data. Upon analysis and processing, the data information is sent to the visualized display platform of the system, and users can directly access the latest agricultural product market information through the website quickly. Meanwhile, the central platform of the system can also issue collection commands and product information to Nongxincai's mobile terminal for achieving remote interaction management.

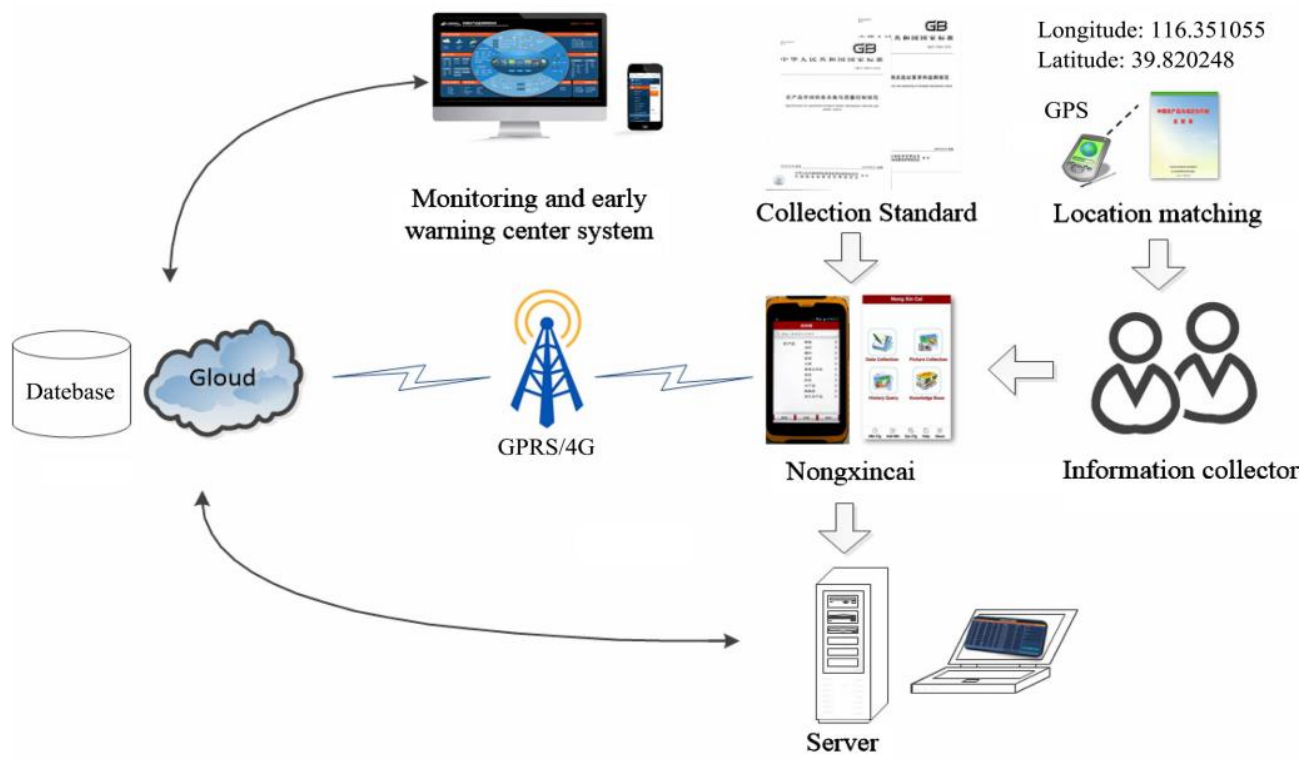

Figure 1 Holographic information collection framework of agricultural product markets

\subsection{Functional features of the data collector}

\subsubsection{Standardized collection of market holographic information}

Agricultural product market information includes a market trading place, trading time, agricultural product name, trading price, trading volume, and other types of information. For a long time, agricultural product market information has had a wide range of types and a broad connotation, which can easily cause ambiguity in the collection and use of information. To address the traditional problems in agricultural product market information that seriously affect information monitoring and the accuracy and reliability of early warnings, such as incomplete content, unknown references, and poor information compatibility, the concept of market holographic information was put forward, the attributes of agricultural products and the interdependence between space and time were discovered and clarified, and a standard system framework of three-dimensional (3D) market information collection with the attributes of price, market, and characteristics was constructed. The holographic information of an agricultural product market refers to the complete information that covers all explicit and implicit information about agricultural products; it maximally covers and comprehensively and multidimensionally expresses the rich informational elements of agricultural products in a way that can meet the needs of agricultural product information in various fields, at various stages, and for various subjects. Based on these considerations, three specifications/ standards for collecting holographic market information of agricultural products were developed; a classification system of market information for 953 agricultural products was established; a complete market information encoding and decoding system was established, in which 11 types of related content (such as trading time, trading place, product name, product price, trading volume, supply quantity, and unit of measurement) are clearly classified and defined; and a standardized method to express holographic information of agricultural product markets was clearly defined. It provides basic technical support for the standardized description of agricultural product market information, for the establishment of a database of agricultural product market information, and the research and development of agricultural product market information services and application systems.

2.2.2 Information collection with real-time positioning and matching

In view of the present shortcomings in the collection of agricultural product market information, including the poor real-time nature, the complex market conditions, and the diversity of wireless network standards, studies on information collection with real-time market positioning and matching, were carried out, mainly based on GPS, GIS, and wireless communication technologies. To meet the needs of information collector personnel in collecting on-site agricultural product market information, we propose a design for automatic positioning and matching of agricultural product market (Figure 3), in which the geographic locations of agricultural product markets are automatically positioned using GPS, followed by one-to-one matching. As shown in Figure 2, according to the type of agricultural product market, market name, market address, main agricultural products, administrative region, market geographic location (longitude and latitude), and collector personnel information, a geographic information association table of the agricultural product market for multiple wholesale markets, field/farm markets, and retail markets in various provinces across China was established. In doing so, the mapping relationship between market information and geographic information was determined, thereby enhancing the geographic calibration of agricultural product markets. In addition, as the network conditions of markets in different regions are complex and variable, a network communication scheme with adaptive selection is conducive to efficient signal transmission ${ }^{[32]}$. Nongxincai integrates multiple wireless communication technologies, establishes a model for network optimization and selection, and enhances the function of the real-time and on-site collection of market information. 


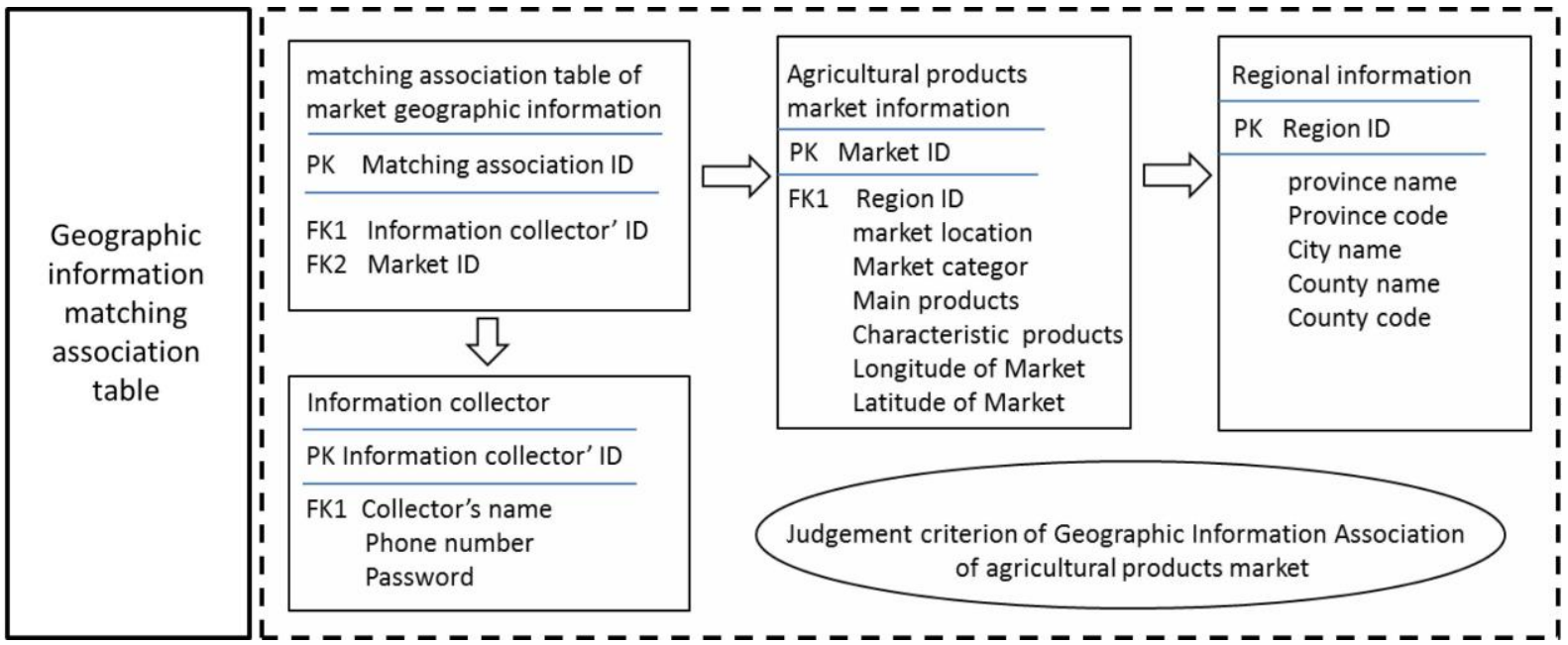

Figure 2 Technological routing of information collection for automatic positioning and matching for agricultural product markets

2.2.3 Data rule base for validation and intelligent analysis/ processing

In view of the problems in the traditional process of agricultural product market information collection (such as inaccuracy in practical operation, difficulty in finding data distortions, and unclarity in personnel assessment), intelligent identification and automatic error correction technology for data collection were developed with a focus on clarifying the process of agricultural product market information collection. According to the collected historical data of agricultural product markets and in combination with changing-curvature analysis, linear analysis, interval adjustment, and other methods, a market data validation rule base, a picture collection rule base, and a product identification rule base were established. On the basis of these rule bases, a model for automatic identification of abnormal data was established, and an automatic early warning system for market information collection was developed. With this, it has achieved automatic data detection, automatic identification, and automatic alarm. Information identification in agricultural product names, product atlases, and product attributes has been promoted, and manual errors in the information collection process have been effectively reduced. The preprocessing and heterogeneous fusion of massive multidimensional data is critical to the accurate and efficient processing of multidimensional heterogeneous data ${ }^{[33]}$. By checking data consistency, processing invalid values and missing values, and applying other data cleaning methods, an optimization model for cleaning up agricultural market data was established to identify missing data and noise in data collection, thereby achieving automatic simulation of missing data, removing abnormal data, and correcting incorrect data. Data collected by Nongxincai are integrated and fused with other important databases of agricultural product market information, a mapping relationship is established for diversified and heterogeneous information about agricultural product markets, and diversified and heterogeneous data are fused, thereby providing a basis for further processing and analysis of agricultural product market information.

\section{Development of an application terminal for Nongxincai}

\subsection{Development of advanced special equipment for collectors}

To meet the practical needs of convenience and mobility for market information collectors, advanced special equipment incorporating convenience, high adaptability, and ease of use was developed based on an innovative design concept. According to the method of embedded mobile development ${ }^{[34]}$, the development and design concept combining the embedded technology and component technology is proposed. Software for market information collection is fully combined with the main body of the hardware and is packaged as an independent system of functional components, which facilitates the plug-and-play of the system and improves the practicability of system applications. The Advanced RISC (reduced instruction set computer) Machines (ARM)-based processor is used as the core to optimize the design of hardware circuits, such as flash memory, GPS module, and RFID module, which promotes the miniaturization of the device. By analyzing the interference and electromagnetic compatibility present in the printed circuit board and by integrating the 3D skeleton design and multi proof control concept, anti-interference and electromagnetic shielding are added to the device circuit, which enhanced the operation stability and environmental adaptability of collection equipment under the conditions of signal interference.

The hardware structure of Nongxincai consists of an embedded processor and various peripheral devices. The schematic diagram of the device structure is shown in Figure 3. The hardware uses a layered structure to integrate a microprocessor module, a memory module, a power supply module, an application and communication interface module, and a human-machine interaction module. The microprocessor module adopts a professional-grade customized UniStrong MG7 Pro processing chip, which has a full hardware video coder-decoder ( $\operatorname{codec}$ ), graphics acceleration, and hardware digital signal processor (DSP) as well as other processors, resembling the multicore design of a personal computer (PC). It is a single-chip micro-PC ( $\mathrm{PC}$ on a chip) with complete inclusion of a central processing unit (CPU), graphics card, and sound card and exhibits excellent actual computing performance. The memory module can be used not only to load various execution programs but also to load new application programs and save various data generated during the running of the programs. Specifically, the random access memory (RAM) storage is $256 \mathrm{MB}$, and it supports MicroSD expansion up to 32 GB.

The overall power consumption of the equipment is $0.5 \mathrm{~W}$, the external power input is $3.3-5 \mathrm{~V}$, and the power supply is a lithium-ion battery (3000 mAh). It supports external power supply and power switching, and the working time is up to $10 \mathrm{~h}$. The application and communication submodules include GPRS and WiFi, Bluetooth V2.0, and GPS; the input and output interfaces are 


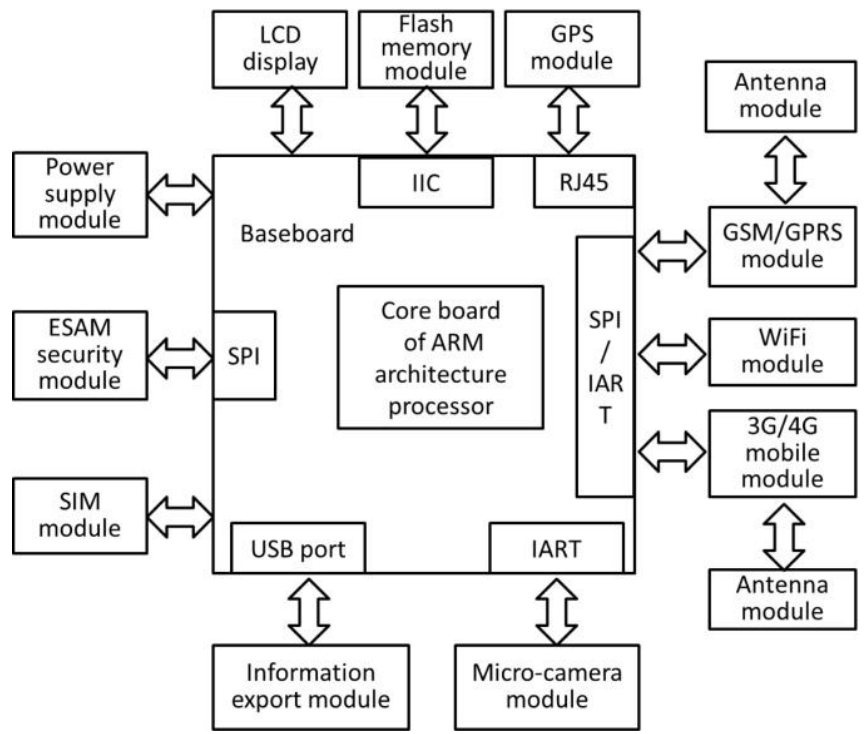

Figure 3 Device structure of Nongxincai

provided/available. In the human-machine interaction module, the screen adopts the latest-generation 3.5-inch quarter video graphics array thin-film transistor liquid-crystal display screen by Casio, and the contents on the screen are clearly visible in the sun. The new BlanView technology is used, such that the outdoor effect outperforms the traditional semitransparent screen. It has a built-in 3-megapixel camera with autofocus that can collect picture data on site to visualize the data collection. A microphone for voice input is built-in. The equipment is designed to be compact and elegant, with a size of $140 \mathrm{~mm} \times 77 \mathrm{~mm} \times 23 \mathrm{~mm}$ (length $\times$ width $\times$ thickness) and a weight of only $191 \mathrm{~g}$. It has robust environmental adaptability with industrial-grade dustproof, waterproof, and shockproof properties. Its operating temperature ranges from $-20^{\circ} \mathrm{C}$ to $60^{\circ} \mathrm{C}$, and its storage temperature is $-30^{\circ} \mathrm{C}$ to $70^{\circ} \mathrm{C}$. Its antiseismic performance is attested by the lack of damage caused by a natural fall from a height of $1.0 \mathrm{~m}$ to the ground; its waterproof and dustproof capabilities reach the IP65 standard.

3.2 Android system development environment and application terminal development

\subsubsection{Software structure}

Application software design based on the Windows Mobile OS is an efficient method for application software development ${ }^{[35,36]}$. Nongxincai's software structure adopts an embedded design (Figure 4) to meet the availability and stability of agricultural production data collection. Specifically, the software structure is mainly composed of an OS layer, a service program layer, and an application program system. As the interface between software and hardware, the OS manages resources and task scheduling in the system. Microsoft Windows Mobile 6.5 is adopted as the OS in Nongxincai, which has a CPU frequency of $600 \mathrm{MHz}$ and can meet the requirements of map processing and large data computation. The advantages of its multithreading, multitasking, fully preemptive OS environment and its open design structure give the software high compatibility, such that it can also provide support for embedded mobile products, even under the conditions of small memory. In addition, the good power management system allows the life of mobile devices to be extended. The standard communication support system allows the use of GSM/GPRS and WiFi Bluetooth V2.0 to achieve wireless communication, access to the Internet, sending of data, and other functions.

\begin{tabular}{|c|c|c|c|c|c|c|c|c|c|}
\hline \multirow{2}{*}{$\begin{array}{l}\text { Application } \\
\text { program layer }\end{array}$} & \multicolumn{5}{|c|}{ System initialization } & \multicolumn{4}{|c|}{ Nongxincai software } \\
\hline & \multicolumn{2}{|c|}{ GPS initialization } & \multicolumn{3}{|c|}{ GPRS initialization } & \multicolumn{3}{|c|}{ Interface function } & $\begin{array}{l}\text { Information } \\
\text { collection process }\end{array}$ \\
\hline \multicolumn{10}{|c|}{ 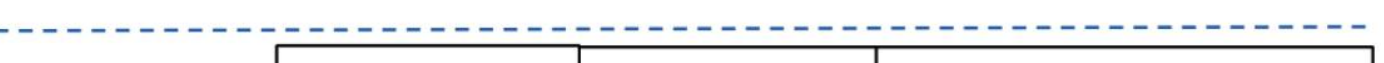 } \\
\hline \multirow{3}{*}{$\begin{array}{l}\text { Service program } \\
\text { layer }\end{array}$} & \multicolumn{2}{|c|}{ Collection standard } & \multicolumn{3}{|c|}{ Hardware driver } & \multicolumn{4}{|c|}{ Interface design } \\
\hline & \multirow{2}{*}{$\begin{array}{l}\text { Collection } \\
\text { specification }\end{array}$} & \multirow{2}{*}{$\begin{array}{c}\text { Information } \\
\text { encoding }\end{array}$} & \multirow{2}{*}{$\begin{array}{l}\text { Touch } \\
\text { screen } \\
\text { drive }\end{array}$} & \multirow{2}{*}{$\begin{array}{c}\text { Memory } \\
\text { drive }\end{array}$} & \multirow{2}{*}{$\begin{array}{l}\text { Serial } \\
\text { Driver }\end{array}$} & \multicolumn{3}{|c|}{ External design } & \multirow{2}{*}{ 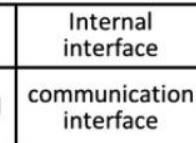 } \\
\hline & & & & & & $\begin{array}{c}\text { operating } \\
\text { system }\end{array}$ & $\begin{array}{l}\text { SQL } \\
\text { Server }\end{array}$ & Excel & \\
\hline $\begin{array}{l}\text { Operating system } \\
\text { layer }\end{array}$ & \multicolumn{9}{|c|}{ Windows Mobile 6.5} \\
\hline
\end{tabular}

Figure 4 Software structure of Nongxincai

\subsubsection{Service program layer}

(1) Embedded standards for the agricultural product information collection

To establish a coordinated and mutually supported standard system for agricultural product information collection, national and industry standards, such as the Specifications For Agricultural Products Market Information Collection and Quality Control (GB/T 35873-2018), Standards of Agri-Product HolographicMarket-Information Collection (NY/T2138-2012), and Classification and Computer Coding of Agri-Product Market Information (NY/T2137-201)", have been developed and embedded in Nongxincai. The embedded standards lay the foundation for the fusion and intelligent processing of collected agricultural product data. For example, the embedded Specifications for Agricultural Products Market Information Collection and Quality Control (GB/T 35873-2018) states that the elements of the holographic information of an agricultural product market mainly include 13 dimensions: trading time, trading place, product name, authentication type, product grade, product origin place, date to market, product price, trading volume, supply quantity, unit of measurement, check code, and quality identification control.

Figure 5 shows the code structure of information coding for agricultural products. The holographic market information coding of each agricultural product contains 13 layers and a 77-digit code, each layer containing a different number of codes. For instance, the code of trading time has 12 digits, the code of trading place has 
10 digits, the code of product name has 13 digits, etc. In this way, the coding rules are in turn established in the Nongxincai software. Specifically, it includes 11 major categories (cereals, oilseeds, sugar, vegetables, fruits, livestock and meat, eggs, dairy, aquatic product, cotton and linen, and other agricultural products) and classification and coding catalogs for 953 major agricultural products. For the classification of agricultural products, six category levels are used: broad-level category, medium-level category, small-level category, fine-level category, product category, and product name. With these coding rules, it is convenient for information collectors to quickly find a given product to be collected.

Table 1 Coding table for holographic information of agricultural product markets

\begin{tabular}{|c|c|c|c|}
\hline Identifier & Element & Format & Description \\
\hline 1 & Trading time & N12 & YYYYMMDDHHMM, accurate to the minute \\
\hline 2 & Trading place & $\mathrm{N} 6+\mathrm{N} 4$ & $\begin{array}{l}\text { When the trading place is a market, a } 6 \text {-digit county code (per GB/T } 2260 \text { )+1-digit market type (1: field/farm market; } \\
\text { 2: place-of-origin wholesale market; } 3 \text { : sales wholesale market; } 4 \text { : supermarket retail market; } 5: \text { stall retail market; } \\
\text { 6: e-commerce; } 7 \text { : futures market)+3-digit code where the market is located (specified by the industry sector) is used. } \\
\text { When trading place is an unfixed market or in the event of no market code, the code is replaced by a 3-digit township code }\end{array}$ \\
\hline 3 & Product name & N13 & Per NY/T2137 \\
\hline 4 & Authentication type & N1 & Authentication type of products (1: normal; 2: no pollution; 3: green; 4: organic; 5: geographic indication; 6: miscellaneous) \\
\hline 5 & Product grade & N1 & Quality grade and specifications of products (1: Excellent; 2: Moderate; 3: Inadequate) \\
\hline 6 & Product origin place & $\mathrm{N} 6+\mathrm{N} 4$ & $\begin{array}{l}\text { 6-digit county code (per GB/T 2260)+1-digit producer type (1: farm household; } 2 \text { : cooperative; } 3 \text { : production enterprise; } \\
\text { 4: warehouse enterprise; } 5 \text { : primary processing enterprise)+3-digit township code (per GB/T10114); when indicating the } \\
\text { place of origin, 6-digit county code + "9"+3-digit market code; imported product code is "999"+3-digit country code (per } \\
\text { GB/T 2659)+4-digit code for region, market, or enterprise }\end{array}$ \\
\hline 7 & Date to market & N8 & YYYYMMDD, the date is recorded \\
\hline 8 & Product price & $\mathrm{N} 4+\mathrm{N} 1$ & $\begin{array}{l}\text { The unit of measurement of product price is the yuan (CNY, RMB); Format using scientific notation, with the first } 4 \text { digits } \\
\text { as significant digits (including } 2 \text { digits after the decimal point) and the last } 1 \text { digit as an exponent of base } 10\end{array}$ \\
\hline 9 & Trading volume & $\mathrm{N} 4+\mathrm{N} 1$ & $\begin{array}{l}\text { Trading volume should generally be expressed in units of mass and coded in scientific notation, with the first } 4 \text { digits as } \\
\text { significant digits (the } 4 \text { digits after the decimal point) and the last } 1 \text { digit as an exponent of base } 10\end{array}$ \\
\hline 10 & Supply quantity & $\mathrm{N} 4+\mathrm{N} 1$ & $\begin{array}{l}\text { Format using scientific notation, with the first } 4 \text { digits as significant digits (the } 4 \text { digits after the decimal point) and the last } 1 \\
\text { digit as an exponent of base } 10\end{array}$ \\
\hline 11 & Unit of measurement & $\mathrm{N} 2$ & $\begin{array}{l}\text { Units of measurement (and coding) for weight are } \mathrm{g}(01), 500 \mathrm{~g}(02), \mathrm{kg}(03) \text {, ton }(04) \text {; unit of measurement (and coding) } \\
\text { for quantity are each (21), head (22), pair (23), piece (24), branch-piece (25), case (26) }\end{array}$ \\
\hline 12 & Check code & $\mathrm{N} 2$ & Calculation method per GB/T 17710 \\
\hline 13 & $\begin{array}{l}\text { Quality identification } \\
\text { control }\end{array}$ & N1 & No quality control (0), correct (1), incorrect (2), suspicious (3), technical correction (6), verification correction (7) \\
\hline
\end{tabular}

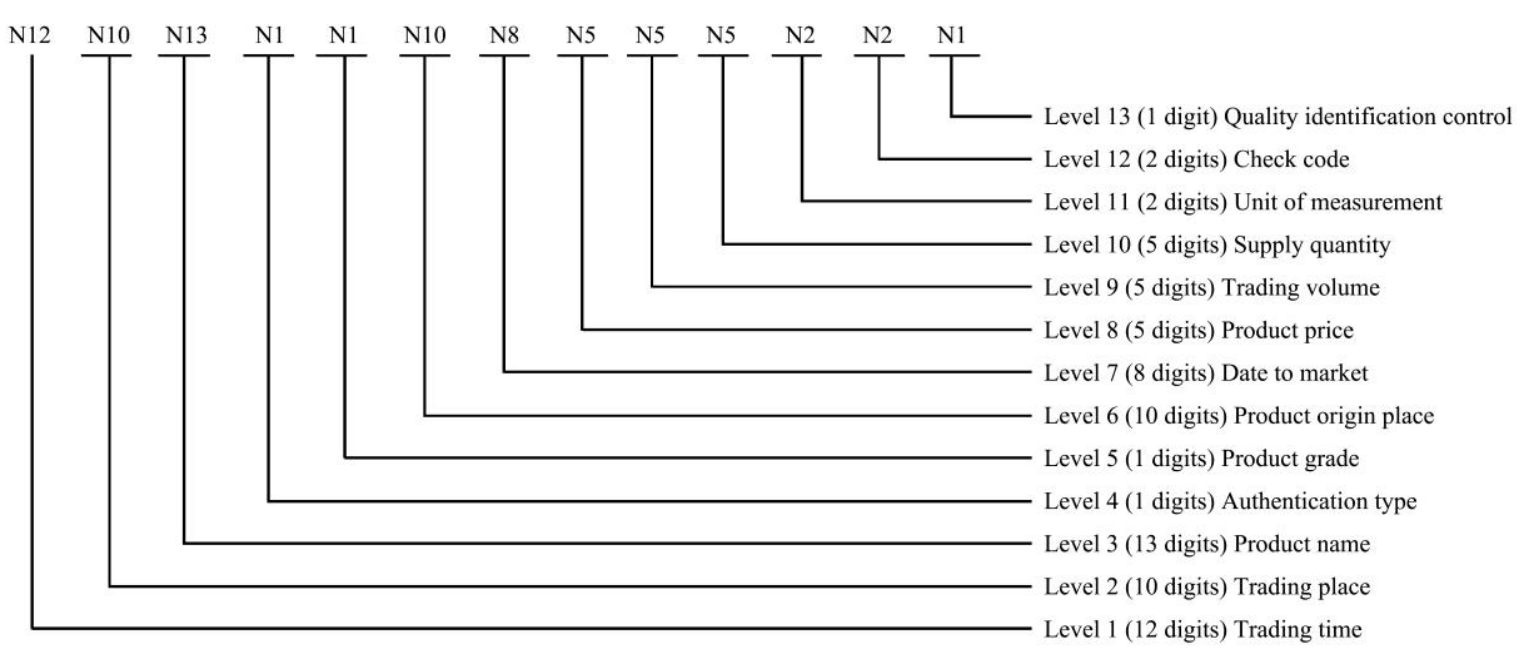

Figure 5 Code structure of information coding for agricultural products

(2) Hardware driver design and interface design

The hardware driver is the guarantor of software operation. This module mainly includes driver programs, such as touch screen driver, memory driver, and serial port driver. The interface design includes the design of the internal interface and the external interface. The internal interface mainly describes the communication interface between Nongxincai and the terminal server system. The external interface includes the interface of Windows OS, the interface of SQL Server, and the interface of Excel. The Windows OS interface is mainly realized through the application program interface function. The SQL Server interface is realized through SQL statements supported by MyEclipse and Visual Studio, and the Excel interface is realized by JavaScript using object linking and embedding (OLE) technology.

3.2.3 Application program layer

The interface of the data collection terminal in Nongxincai is shown in Figure $6 . \quad$ It is user-friendly and has strong human-computer interaction. The collection software is developed based on the Windows Mobile technology and is implemented in the Visual Studio 2008 development environment with the C\# language. The application layer mainly includes the system initialization program and market information collection program. The system initialization program mainly includes GPS positioning and GPRS program initialization. The GPS module has a built-in professional GPS engine and high-sensitivity GPS antenna (micro-miniature coaxial (MMCX) straight interface). It 
uses the NMEA0183 data protocol for accurate real-time positioning (two-dimensional root mean square (2DRMS) of 2-5 m (2DRMS); a satellite-based augmentation system (SBAS) 2DRMS of 1-3 m). In Nongxincai, GPS is used to automatically match the information collection address, thereby eliminating the step of inputting the market where information collection is conducted and ensuring the authenticity of data collected on site.

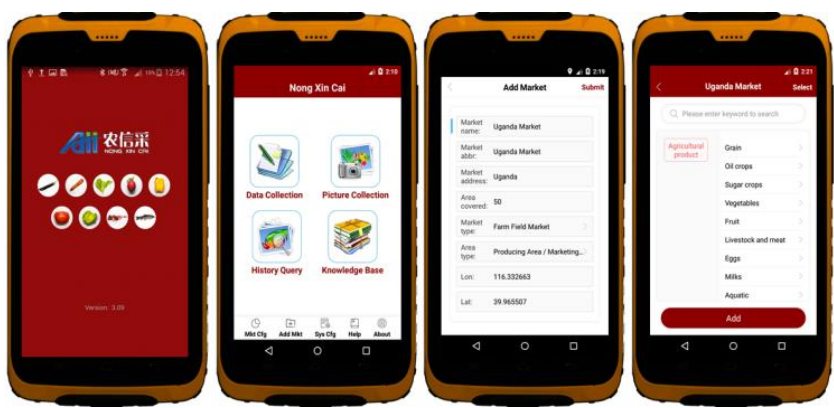

Figure 6 Terminal interface of data collection in Nongxincai

\section{Results and discussion}

4.1 Standardized and high-efficiency collection of holographic information of agricultural product markets

4.1.1 Standardized collection of holographic information of agricultural product markets

The agricultural product market has diverse transmission formats, complex wireless network conditions, and data security issues readily caused by frequent interceptions of sensitive information. Therefore, in this study, an encoding and decoding strategy for agricultural product market information is proposed. On the basis of information classification and combined with hierarchical coding and feature combinatorial coding ${ }^{[37,38]}$, a complete encoding and decoding system for agricultural product market information was established, and an encoding and decoding module for agricultural product market information was developed. It converts agricultural market collection data into a 13-layer, 77-digit code for transmission and solves the security problem in data transmission. To improve the fault-tolerance rate of the check code and analyze the basic characteristics of the digital encoding, an automatic generation and identification system for market information check codes were constructed based on the ISO 7064 MOD97-10 check code, which effectively solves single-character substitution, swap, displacement, and other errors, thereby improving the quality of data transmission.

The coding rules and relevant standards of agricultural product collection, which promote the standardized and normalized data collection from wholesale markets designated by the Ministry of Agriculture and Rural Affairs of China, have been widely used in China. As a result, the comparability of agricultural product market information data across different regions and the data quality of agricultural product markets in China have been greatly improved. The application and popularization show that the data collection efficiency of Nongxincai is greatly improved over traditional equipment and methods, and the data loss rate is controlled within $1 \%$, which has played an important technical support role in the advancement of China's information collection technology for agricultural product markets. Figure 7 shows a screenshot of the interface for real-time price data collection in Nongxincai. As shown in the figure, the collection time was 6:43 a.m. on Dec 24, 2019. The market was Hada wholesale market A in Nangang District, Harbin, Heilongjiang Province, China. The price information of important agricultural products, such as large radish, carrot, cabbage, eggs, and pepper, was collected and reported in real-time. Compared with traditional market information collection, holographic information in Nongxincai can be increased to 13 types of indicators with a high collection accuracy, which effectively avoids the repeated entry of collected subjects and greatly simplifies the operation steps, thereby improving the forecast/early warning accuracy and intelligence level of agricultural product market information.

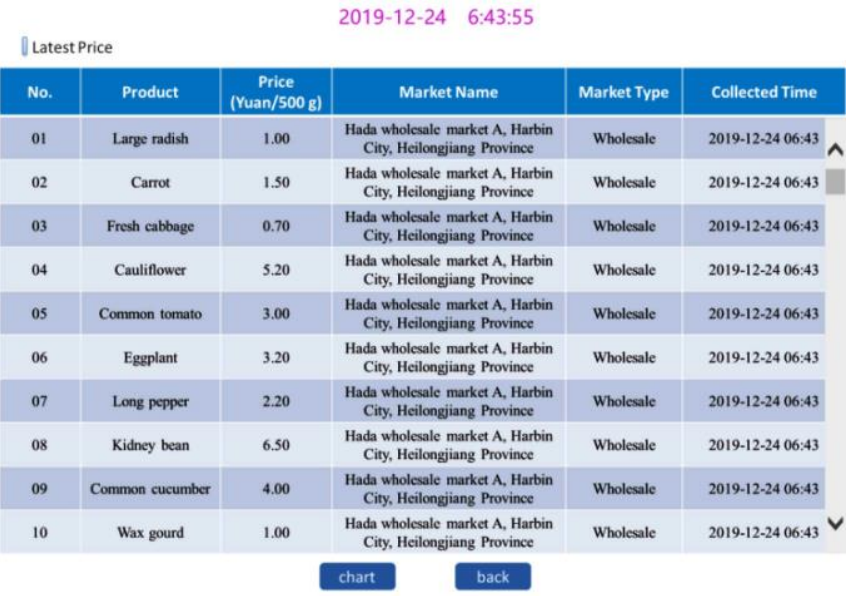

Figure 7 Demonstration of real-time price data collection in Nongxincai

4.1.2 Real-time positioning collection of agricultural product market information

Agricultural product market information collection has its complexities. First, there are many types of markets, including field/farm markets, wholesale markets, retail markets, and supermarkets. The prices of agricultural products differ between market types, and the grades of these products have large gaps. Second, the variety of agricultural products is diverse. There are even multiple brand types for the same agricultural product. Furthermore, the main varieties and agricultural product prices in different regional locations are very different.

Hence, representative markets were selected from nationwide markets, and an association table was established for the geographic information of agricultural product markets, including multiple wholesale markets, field/farm markets, and retail markets. GPS positioning technology was used to obtain the latitude and longitude of agricultural product markets subjected to collection operations, providing the advantages of automatic positioning and on-site matching in agricultural product markets. In terms of the timeliness of information collection, by integrating a variety of wireless communication technologies, Nongxincai allows all-weather and real-time collection of market information and achieves the realization of real-time geographic information and spatial analysis of agricultural product market information.

Data collection is the core module of Nongxincai, and the core business process of data collection in Nongxincai is shown in Figure 8. During data collection, a request is sent to the server based on the current latitude and longitude to make a query for displaying information about all the collection markets within $1 \mathrm{~km}$ of the current latitude and longitude. If there is a market need to collect information and prior information is already present in the system, the data are collected; otherwise, the interface jumps to the page for adding a market, and the market information is added, which is then saved to the server terminal. Next is data collection, and the data are transmitted once the collection is completed. If it is the first time for a given user to report the collected data, the 
system will prompt the user to provide identification authentication. If the login is successful, the data will be transmitted to the server. In addition, Nongxincai can also use the photo acquisition module to collect and manage photos and use the knowledge base and historical query function to help with the collection of agricultural product information. At present, Nongxincai has been promoted and applied in 12 provinces (municipalities, autonomous regions) in China, including Tianjin, Fujian, Heilongjiang, and Hainan, indicating that it has played an important role in agricultural product market information collection and in supporting regulatory decision-making in China ${ }^{[39-41]}$.

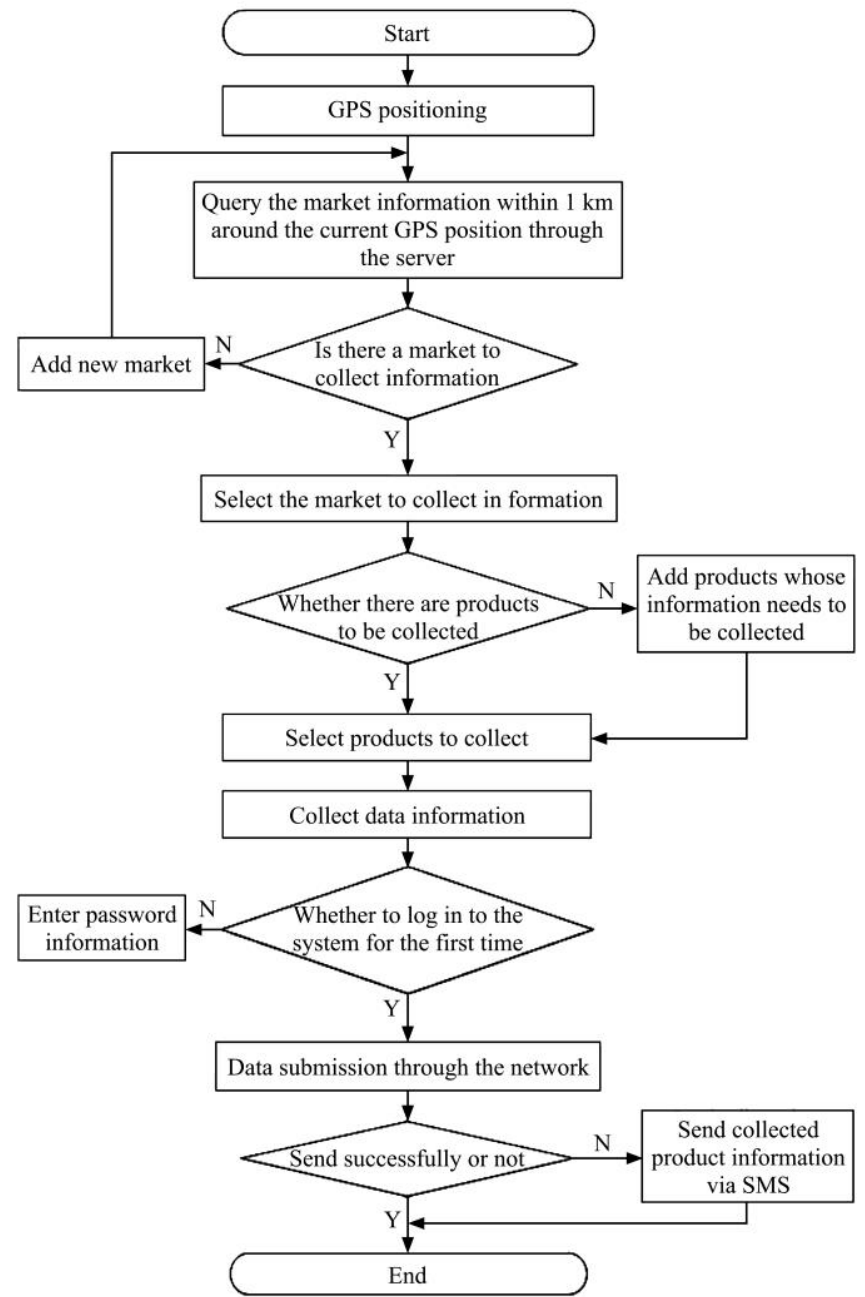

Figure 8 Flowchart of the core business of data collection in Nongxincai

4.2 Autonomous identification of abnormal data and data rule validation and cleaning

Due to the geographical distribution of agricultural product markets, the uneven quality of collector personnel, and the numerous elements in agricultural product information collection, agricultural product market information collection is complex. Hence, it is important to ensure the authenticity, effectiveness, and comparability of data collection. There is an urgent need to develop an independent error correction technology in accordance with the characteristics of the agricultural product market, which can independently identify abnormal data and ensure the accuracy of data collection.

Using data reduction methods, high-dimensional data can be dimensionally reduced and sampled, and the characteristic dimensions of the data can be highlighted. Along with reducing the amount of data, maintaining the homogeneity of data is very important to improve the efficiency and pertinence of data processing ${ }^{[42,43]}$. In view of the issues present in the traditional process of agricultural product market information collection, such as unclarified collection rules, uneven quality of collector personnel, and misoperation and error collecting, studies on intelligent identification and automatic error correction of collected data have been carried out. Data calculation methods are used, such as Leyte's criterion ${ }^{[44,45]}$.

$$
\begin{gathered}
\left|V_{i}\right|=\left|X_{i}-\bar{X}\right| \\
\delta=\sqrt{\frac{1}{n-1} \sum_{i=1}^{n} v_{i}^{2}}
\end{gathered}
$$

By focusing on the analysis and calculation process of agricultural product market information collection, using the collected historical data of agricultural product markets, and in combination with methods such as change curvature, linear analysis, and interval adjustment, a market data validation rule base, a picture collection rule base, and a product use identification rule base can be established. Nongxincai has two ways to autonomously identify and correct abnormal data. First, an automatic data identification model has been built based on the rule base. Second, an automatic early warning system for input errors of market information has been developed. The early warning system has functions of automatic data detection, identification, and error reminders. If abnormal data are input by collector personnel, an input box as a reminder is immediately sent, which can effectively reduce the error rate of the collector personnel during the information collection process. Third, upon data collection, the system reanalyzes the data and reminds the administrator of data with a large increase/decrease from the previous month/time.

Figure 9 shows the market price data of Fuji apples collected in a market information collection site for the past six months (Jun. 2019-Dec. 2019), and the overall apple price shows a trend of stabilization followed by a decline. The oval in the figure shows that the price on Aug 11 of 32 Yuan/kg was much different from the other prices for the same product. In this scenario, this abnormal data point is automatically identified, and a reminder is sent to the administrator. Through the reminder information, the administrator identifies the contact information of the collector personnel to check the data. If it is found to be an error upon data checking, this error can be removed to ensure the authenticity and validity of the collected data. In addition, by using data encryption technology and data disaster-recovery technology as well as developing intrusion detection components in data transmission, the risk of market information network attack is effectively reduced.

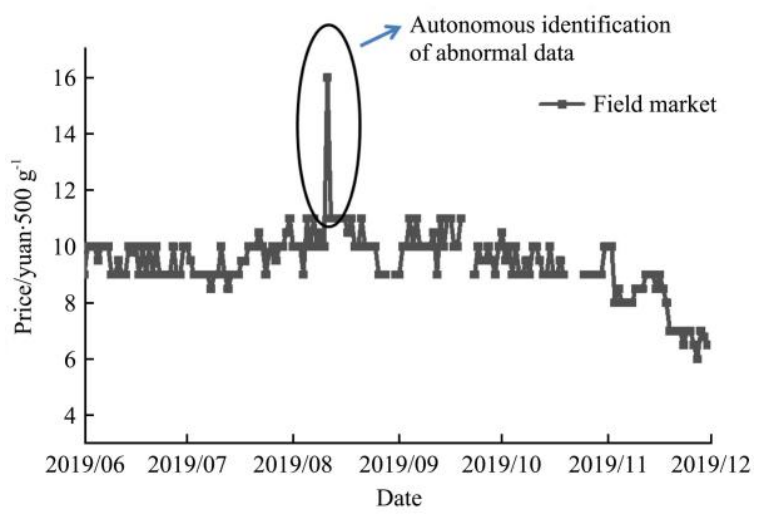

Figure 9 Autonomous identification of an abnormal apple price 
4.3 Nongxincai index establishment and intelligent prediction of and early warning about market information

To accurately grasp the dynamics of agricultural product markets, based on the real-time data of market holographic information collected by Nongxincai and by adopting big-data fusion analysis processing and index calculation methods, the Nongxincai forecast and early warning index was established. The difficulty in establishing the price index through daily Nongxincai data lies in several factors: complicated data classification, poor continuity of data between days, and inconstant agricultural product varieties reported daily. The daily Nongxincai price data can be written as an $m \times n$-dimensional matrix $A(m$ is the time dimension and $n$ is the product variety dimension). The matrix is then a typical sparse matrix. Sparse matrices have been widely used in eigenvalue extraction, behavior discrimination, and face recognition ${ }^{[46,47]}$. In this study, the price index of agricultural products is expressed mathematically as follows:

$$
A_{m \times n} \cdot w_{n \times 1}=N I_{m \times 1}
$$

where, $A_{m \times n}$ is the price matrix; $w_{n \times 1}$ is the weighting vector of various agricultural products, and $N I_{m \times 1}$ is the vector of Nongxincai indices on the $m$ th day.

Due to large differences in collection amounts between product varieties, the characteristics of 11 major categories of agricultural products are taken into account, and the weight is thus assigned by the root weight method:

$$
w_{i}=\frac{\varepsilon_{i} \cdot \sqrt{Q_{i}}}{\sum \varepsilon_{i} \cdot \sqrt{Q_{i}}}
$$

where, $Q_{i}$ is the total amount of data collected for each type of agricultural product, and $\varepsilon_{i}$ is the core hotspot coefficient for each type of agricultural product. The core hotspot coefficient indicates the ratio of production and consumption for a given major category of agricultural products and its hotness degree in the current year. The larger the coefficient is, the higher the weight of the corresponding category of agricultural products.

According to the data after 2015, the weights of 11 major categories of agricultural products are calculated, as shown in Table 2.

Table 2 Weights of 11 major agricultural products

\begin{tabular}{lcccc}
\hline \multicolumn{1}{c}{ Varieties } & 2015 & 2016 & 2017 & 2018 \\
\hline Cereals & 0.1253 & 0.1286 & 0.1285 & 0.1269 \\
Oilseeds & 0.0757 & 0.0709 & 0.0710 & 0.0713 \\
Sugar & 0.0160 & 0.0165 & 0.0160 & 0.0143 \\
Vegetables & 0.2979 & 0.3088 & 0.3060 & 0.3083 \\
Fruits & 0.1705 & 0.1636 & 0.1707 & 0.1696 \\
Livestock and meat & 0.1376 & 0.1370 & 0.1343 & 0.1343 \\
Eggs & 0.0662 & 0.0640 & 0.0620 & 0.0636 \\
Dairy & 0.0138 & 0.0145 & 0.0143 & 0.0146 \\
Aquatic products & 0.0822 & 0.0800 & 0.0800 & 0.0802 \\
Cotton and linens & 0.0099 & 0.0111 & 0.0120 & 0.0116 \\
Other & 0.0049 & 0.0050 & 0.0052 & 0.0053 \\
\hline
\end{tabular}

Taking the vector of core hotspot coefficients $\varepsilon=[1,1,1,1,1,1$, $1,1,0.6,1,0.1]$, the Nongxincai price index is designed with reference to the chain price index. Taking 2015 as the base year, the weights of 11 major categories of agricultural products can be calculated from information collected for all agricultural products in the previous year. The specific agricultural products included in the calculation in a given year are determined based on the collection amount for each agricultural product in the previous year. With regard to collection amount, the top 20 for cereals; the top 10 for oilseeds; sugar cane and beet as the sugar category; the top 30 for vegetables; the top 30 for fruits; the top 30 for livestock/poultry and meat; the top 5 for poultry eggs; sterilized milk as dairy products; the top 20 for aquatic products; fine-cotton wool and long-cotton wool as cotton and linens; and the other top 10 miscellaneous categories were selected. Each agricultural product within a given major category is given equal weight.

For example, the Nongxincai price index for the $i$ th day in the year 2016 is calculated as follows:

$$
N I_{i}=\frac{\sum_{j} P_{\mathrm{i}, j} \cdot w_{2015, j}}{\sum_{j} P_{2015, j} \cdot w_{2015, j}} \times 100
$$

where, $N I_{i}$ is the Nongxincai price index on the $i$ th day; $P_{i, j}$ is the $j$ th agricultural product on the $i$ th day; $w_{2015, j}$ is the weight of the $j$ th agricultural product in 2015, and $P_{2015, j}$ is the average price of the $j$ th agricultural product in 2015.

The Nongxincai price index on the $i$ th day in 2017 is

$$
N I_{i}=\frac{\sum_{j} P_{2016, j} \cdot w_{2015, j}}{\sum_{j} P_{2015, j} \cdot w_{2015, j}} \times \frac{\sum_{j} P_{i, j} \cdot w_{2016, j}}{\sum_{j} P_{2016, j} \cdot w_{2016, j}} \times 100
$$

Likewise, the Nongxincai price index on the $i$ th day in year $y$ $(y \geq 2017)$ is

$$
N I_{I}=\left(\prod_{\text {year }=2015}^{Y-2} \frac{\sum_{j} P_{\text {year }+1, j} \cdot w_{\text {year }, j}}{\sum_{j} P_{\text {year }, j} \cdot w_{\text {year }, j}}\right) \times \frac{\sum_{j} P_{i, j} \cdot w_{y-1, j}}{\sum_{j} P_{y-1, j} \cdot w_{y-1, j}} \times 100
$$

If an agricultural product included in the index calculation has no collection price on the current day, the collection price on the previous day is used. This step is taken successively. If the agricultural product has no collection price in the current year, then the average collection price of the previous year is adopted.

Figure 10 shows the trend chart of the Nongxincai price index for supermarkets in the past year (Dec. 2018-Dec. 2019), which was intelligently generated based on the algorithm. The index shows that the agricultural product market in China showed a trend of stabilization followed by an increase over the past year, and growth has been accelerating since July 2019. The Nongxincai price index for supermarkets was increased by $22.0 \%$ in 2019 . The Nongxincai index established according to this method considers the updates of similar products, i.e., the frequent updates of new product listings and old product delistings, and thus outperforms the conventional method in tracking the prices of existing products on the market. It has higher accuracy, can better reflect the real operation situation of markets and can forecast and provide early warnings for future trends. In the future, with the continuous in-depth integration of artificial intelligence (AI) and agricultural scenarios, technologies such as voice perception, visual

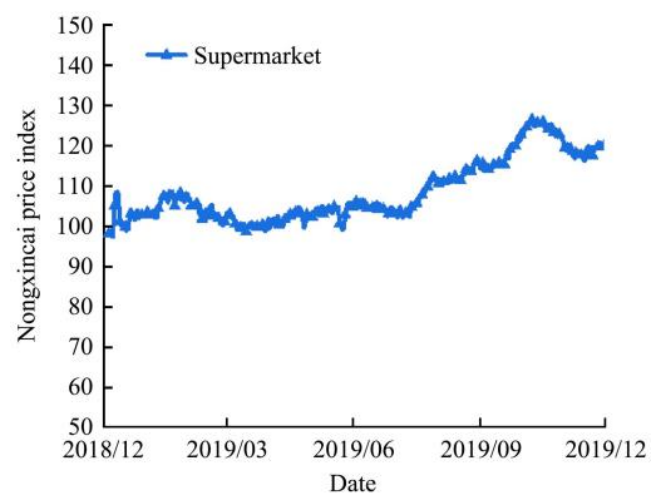

Figure 10 Nongxincai price index trend in the past year 
perception, and immersive experience will be further applied in information collectors, thereby improving the information collection efficiency of the collector. In addition, the self-learning ability of the forecasting/early warning system may be further improved to provide strong support for intelligent monitoring of and early warning about agricultural product markets.

\section{Conclusions}

In this study, a portable, user-interactive information collector for agricultural product markets, called Nongxincai, was developed. Nongxincai has robust functions, including a standardized collection of market holographic information, real-time location matching collection, data validation, and autonomous identification of abnormal data. It allows instantaneous collection of information in 13 dimensions, such as trading time, product price, and trading volume of agricultural product markets.

(1) By embedding the developed collection standards for agricultural product market information, market information classification models and classification components for 953 agricultural products were developed, and the rapid standardized collection, classification, and storage of massive market data were achieved. The collection of agricultural product market information has some special complexities. For example, the market types are diverse, the varieties of agricultural products are diverse, and regional locations vary greatly. The embedding of standards in the collection equipment is conducive to the large-scale comparison of large amounts of data and improves the utilization value density of collected data.

(2) An association table for the geographic information of agricultural product markets was established, which in combination with the GPS positioning module ensures the automatic positioning and on-site matching of agricultural product markets. A market data validation rule base was established to allow the equipment to identify abnormal data autonomously. The ability of autonomous error correction to ensure the accuracy of data collection is also an important aspect of improving the accuracy of data collection.

(3) Advanced special equipment was developed with the advantages of convenience, high environmental adaptability, and ease of use. With this equipment, information can be conveniently collected in various types of markets and by collectors with various educational levels, allowing a greatly improved efficiency of data collection over traditional methods. Hence, the environmental adaptability of the collection equipment is one important improvement in market data collection.

(4) The Nongxincai index was established, and a system with the capacity of self-learning for agricultural product price forecasting and early warning was established, which effectively eases the difficulty in issuing early warnings during the early period of agricultural product price fluctuation. In the future, with the continuous in-depth fusion of AI and agricultural scenarios, technologies such as voice perception, visual perception, and immersive experience will be further applied in information collectors, and the information collection efficiency will be further improved.

Nongxincai has been applied in 12 provinces/municipalities in China, and the number of users has continued to increase rapidly. It has played an important role in the monitoring and early warning of agricultural product market information. It has become a general technology that the Ministry of Agriculture and Rural Affairs has used to carry out the monitoring of agricultural products by variety, and it has also been employed by the Development and
Reform Commission of China to monitor the target price of cotton and soybean.

\section{Acknowledgements}

Project funded by Special fund for Agricultural Information Monitoring and Early Warning of the Ministry of Agriculture and Rural Affairs, China; Scientific and technological innovation project of the Chinese Academy of Agricultural Sciences, China (CAAS-ASTIP-2019-AII-01); National Key Research and Development Project (2016YFD0300602); Young Elite Scientists Sponsorship Program by CAST( 2019-2021QNRC001).

\section{[References]}

[1] Huang J K, Yang J, Chou H G, Xu Z G. The great ups and downs of grain prices of this round: The main reasons and the future trend. Management Word, 2009; 1: 72-78.

[2] Xu S W, Li G Q, Li Z M. China agricultural outlook for 2015-2024 based on China Agricultural Monitoring and Early-warning System (CAMES). Journal of Integrative Agriculture, 2015; 14(9): 1889-1902.

[3] Pang Z B, Chen Q, Han W L, Zheng L R. Value-centric design of the internet-of-things solution for food supply chain: Value creation, sensor portfolio and information fusion. Information Systems Frontiers, 2015; 17: 289-319.

[4] Zhang B, Zhang W, Qi L Q, Fu H B, Yu L, Li R, et al. Information acquisition system of multipoint soil surface height variation for profiling mechanism of seeding unit of precision corn planter. Int J Agric \& Biol Eng, 2018; 11(6): 58-64.

[5] Vijay G, Bdira E B A, Ibnkahla M. Cognition in wireless sensor networks: A perspective. IEEE sensors journal, 2011; 11(3): 582-592.

[6] Deng M X, Di L P, Han W G, Yağcı A L, Peng C M, Heo G Web-service-based monitoring and analysis of global agricultural drought. Photogrammetric Engineering \& Remote Sensing, 2013; 79(10): 929-943.

[7] Yin Y X, Chen L P, Meng Z J, Li B, Luo C H, Fu W Q, et al. Design and evaluation of a maize monitoring system for precision planting. Int $\mathrm{J}$ Agric \& Biol Eng, 2018; 11(4): 186-192.

[8] Walter A, Finger R, Huber R, Buchmann N. Opinion: Smart farming is key to developing sustainable agriculture. PNAS, 2017; 114(24): 6148-6150.

[9] Qin Z, Compton B G, Lewis J A, Buehler M J. Structural optimization of 3D-printed synthetic spider webs for high strength. Nature Communications, 2015; 6: 7038.

[10] Yu H, Yang J L, Sun Y X. Energy absorption of spider orb webs during prey capture: A mechanical analysis. Journal of Biomimetic Engineering, 2015; 12(3): 453-463.

[11] Liu J G, Zhao C J, Yang G J, Yu H Y, Zhao X Q, Xu B, et al. Review of field-based phenotyping by unmanned aerial vehicle remote sensing platform. Transactions of the CSAE, 2016; 32(24): 98-106. (in Chinese)

[12] He Y, Nie P C, Liu F. Advancement and trend of internet of things in agriculture and sensing instrument. Transactions of the CSAM, 2013; (10): 216-226. (in Chinese)

[13] Misra S, Krishna P V, Saritha V, Agarwal H, Shu L, Obaidat M S Efficient medium access control for cyber-physical systems with heterogeneous networks. IEEE systems journal, 2015; 9(1): 22-30.

[14] Ruiz G L, Lunadei L. The role of RFID in agriculture: applications, limitations and challenges. Computers and Electronics in Agriculture, 2011; 1(1): 42-50.

[15] Oliveira J L., Xin H W, Wang K L, Zhao Y. Evaluation of nesting behavior of individual laying hens in an enriched colony housing by using RFID technology. Int J Agric \& Biol Eng, 2019; 12(6): 7-15.

[16] Ahumada O, Villalobos J R, Mason A N. Tactical planning of the production and distribution of fresh agricultural products under uncertainty. Agricultural Systems, 2012; 112: 17-26.

[17] Li Z R. Design of aquaculture network monitoring system based on embedded Linux. Journal of Agricultural Mechanization Research, 2019; 41(11): 229-233. (in Chinese)

[18] Sun X, Yang Y S, Liu C X, Guo H P. Design and development of near field communication intelligent data acquisition terminal system in fresh agricultural product supply chain. Transactions of the CSAE, 2015; 31(8): 200-206. (in Chinese)

[19] Xu S W. Agricultural big data and monitoring and early warning of 
agricultural products. Journal of Agricultural Science and Technology, 2014; 16(5): 14-20. (in Chinese)

[20] United States Department of Agriculture. https://www.usda.gov/.

[21] Australian Department of Agriculture. https://www.agriculture.gov.au/.

[22] Australian Bureau of Statistics. https://www.abs.gov.au/.

[23] Commonwealth Scientific and Industrial Research Organisation (CSIRO). https://www.csiro.au/

[24] Agriculture, forestry and fisheries. http://www.maff.go.jp/.

[25] Zhao Y S, Wang X D, Zhao A P, Ge X S. Research on the construction of information system of foreign agricultural products market. World Agriculture, 2012; 10: 36-41.

[26] Singh G, Junghare A, Chokhani P. Multiutility E-controlled cum voice operated farm vehicle. International Journal of Computers \& Applications, 2010; 1(13): 109-113.

[27] Plauche M, Nallasamy U, Pal J, Wooters C, Ramachandran D. Speech recognition for illiterate access to information and technology. 2006 International Conference on Information and Communication Technologies and Development, Berkeley: IEEE, 2006; pp.83-92.

[28] Daniel S, Daniel P, Jochen S. REST-based meta web services in mobile application frameworks. The Fourth International Conference on Mobile Ubiquitous Computing, Systems, Services and Technologies (UBICOMM2010), 2010; pp.170-175.

[29] Owusu A B, Yankson P W K, Frimpong S. Small holder farmers' knowledge of mobile telephone use: Gender perspectives and implications for agricultural market development. Progress in Development Studies, 2018; 18(1): 36-51.

[30] Nakasone E, Torero M, Minten B. The power of information: The ICT revolution in agricultural development. Annual Review of Resource Economics, 2013; 6(1): 533-550.

[31] See L D, Fritz S, You L Z. Improved global cropland data as an essential ingredient for food security. Global Food Security, 2015; 4: 37-45.

[32] Sydney A, Scoglio C, Gruenbacher D. Optimizing algebraic connectivity by edge rewiring. Applied Mathematics and computation, 2013; 219(10): 5465-5479.

[33] Song A B, Wan Y T, Gong H, Xue Y Y. Research on storage and query of large-scale multidimensional data. Computer Engineering and Applications, 2016; 52(13): 25-31.

[34] Qu B, Wu Z Z. Design of ARM based embedded operating system micro kernel. Applied Mechanics and Materials, 2013; 347-350: 1799-1803.

[35] Zhang S R, Zheng W G, Shen C J, Xing Z. Agricultural product price Information collection terminal of embedded portable wireless. Computer Engineer and Design, 2012; 33(2): 514-518.

[36] Zheng L X. Embedded Linux system design. Beijing: Beijing University of Aeronautics and Astronautics Press, 2008; pp.195-200.

[37] Yuan J P, Chen K, Huang J, Li L H, Yang Y, Zhu D H, et al. A nove generic concept hierarchy encoding algorithm. Computer Engineering, 2006; 32(12): 17-21. (in Chinese)

[38] Cui Y, Duan F, Zhang Y J. Scene classification based on coding layer feature combination. Journal of Jilin University (Engineering and Technology Edition), 2013; 43: 450-454. (in Chinese)

[39] Xin L Y, Wang L J, Song Z W, Jia B H. Research on popularization and application of "Nongxincai" software in Tianjin. Tianjin Agricultural Sciences, 2017; 23(6): 45-47. (in Chinese)

[40] Liu J H. Research on popularization and application of "portable market information collector for agricultural products" in Fujian Province. Fujian Agricultural Science and Technology, 2015; 8: 82-84. (in Chinese)

[41] Li Y, Wang H L, Zhang Y, Zhang H F, Zhang Y, Wang X N. The analysis of vegetable prices fluctuation in Heilongjiang Province based on the data of "agricultural credit". Vegetables, 2018; 1: 66-70. (in Chinese)

[42] Cheng L Q. Research on the effect of data constraint on data quality. Journal of Yangtze University (Nature Science Edition), 2011; 8(5): 100-102. (in Chinese)

[43] Liu J J, Cao W J. Data quality management strategy in large data environment. Software Guide, 2017; 16(3): 176-179. (in Chinese)

[44] Du Y X, Zhang Z T, Li B S, Qin L. Design of Hulun Lake environment information acquisition system based on letts criterion improved algorithm. Modern Electronics Technique, 2016; 39(24): 30-33.

[45] Wu Y L, Yang Na, Pan X H, Wang W H. Temperature and humidity detection system based on letts criterion and data fuse. Bulletin of Science and Technology, 2017; 33(3): 96-99. (in Chinese)

[46] Zeng W, Zhao Y H. Parallel eigenvalue calculation based on spectrum division method for sparse matrix. Journal on Numerical Methods and Computer Applications, 2015; 36(2): 132-141. (in Chinese)

[47] Yang G L, Luo L, Lu H R, Feng Y Q, Liang L M. Face recognition based on matrix regression with low rank and e-p sparse constraints. Computer Science, 2015; 42: 180-184. (in Chinese) 